\title{
Walking Improves the Performance of a Brain-Computer Interface for Group Decision Making
}

Bhattacharyya, S., Cinel, C., Citi, L., Valeriani, D., \& Poli, R. (2019). Walking Improves the Performance of a Brain-Computer Interface for Group Decision Making.

Link to publication record in Ulster University Research Portal

Publication Status:

Published (in print/issue): 16/07/2019

\section{Document Version}

Author Accepted version

\section{General rights}

Copyright for the publications made accessible via Ulster University's Research Portal is retained by the author(s) and / or other copyright owners and it is a condition of accessing these publications that users recognise and abide by the legal requirements associated with these rights.

\section{Take down policy}

The Research Portal is Ulster University's institutional repository that provides access to Ulster's research outputs. Every effort has been made to ensure that content in the Research Portal does not infringe any person's rights, or applicable UK laws. If you discover content in the Research Portal that you believe breaches copyright or violates any law, please contact pure-support@ulster.ac.uk. 


\title{
WALKING IMPROVES THE PERFORMANCE OF A BRAIN-COMPUTER INTERFACE FOR GROUP DECISION MAKING
}

\author{
Saugat Bhattacharyya ${ }^{1, *}$, Caterina Cinel $^{1}$, Luca Citi $^{1}$, Davide Valeriani ${ }^{2}$ and Riccardo Poli ${ }^{1}$ \\ ${ }^{1}$ BCI-NE Lab, School of Computer Science and Electronic Engineering, University of Essex, \\ Colchester, UK \\ ${ }^{2}$ Department of Otolaryngology, Massachusetts Eye and Ear, Harvard Medical School, Boston, MA, \\ USA \\ *saugat.bhattacharyya@essex.ac.uk
}

\begin{abstract}
We show that walking on a treadmill improves the performance of an EEG-based collaborative brain-computer interface $(\mathrm{cBCI})$ for assisting group decision making.

\section{INTRODUCTION}

Collaborative brain-computer interfaces (cBCIs) have been used to improve group decision making thanks to their ability to estimate the decision confidence of individuals from their brain signals and response time (RT) [1-3]. However, previous studies used the $\mathrm{cBCI}$ in controlled lab conditions, where users performed limited muscular activity while making decisions. Here, we developed and tested a cBCI in situations where users perform decision-making tasks while walking on a treadmill.
\end{abstract}

\section{METHODS}

Ten participants were presented with video sequences (frame rate $=4 \mathrm{~Hz}$ ) of a dynamic environment representing the viewpoint of a user walking at a constant pace along a corridor, where characters could appear from side doorways for one frame (Fig. 1 (left)). In each trial, the participants had to decide whether the character was wearing a helmet or a cap within $2.5 \mathrm{~s}$. After reporting their decisions, participants had to indicate their degree of confidence using an 11-point scale (from $0=$ not confident, to $100=$ very confident) within $2 \mathrm{~s}$. The experiment was composed of 12 blocks of 42 trials: six blocks where the participant was walking on a treadmill in a leisurely manner $(2 \mathrm{~km} / \mathrm{h})$, and six blocks where he/she was sitting on a comfortable chair, in a counterbalanced order. A Biosemi ActiveTwo EEG system was used to record the neural signals from 64 electrode sites following the 10-20 international system. The EEG data were sampled at $2048 \mathrm{~Hz}$, referenced to the mean of the electrodes placed on the earlobes, and band-pass filtered between 0.15 to $40 \mathrm{~Hz}$ to reduce electrical noise. Decision confidence was estimated by logistic regression using the RT and two neural features, extracted by applying Common Spatial Patterns filters to low-pass filtered $(16 \mathrm{~Hz})$ response-locked EEG epochs starting $1 \mathrm{~s}$ before the response and lasting $1.5 \mathrm{~s}$. The data collected from the participants were then combined off-line to form all possible groups of increasing size.

\section{RESULTS}

Fig. 1 (right) shows the mean accuracies for group sizes one to five using either standard majority (black) or a weighted majority using the confidence reported by the participant after each decision (blue) or the confidence estimated by the cBCI (red), for the walking (solid lines) and sitting (dashed lines) conditions. This shows that $\mathrm{cBCI}$ and reported confidence produce similar results, but walking improves the group performance statistically significantly ( $p<0.03$ for Wilcoxon signed-rank tests) for reported confidence and $\mathrm{cBCI}$ when compared to the corresponding sitting conditions. 

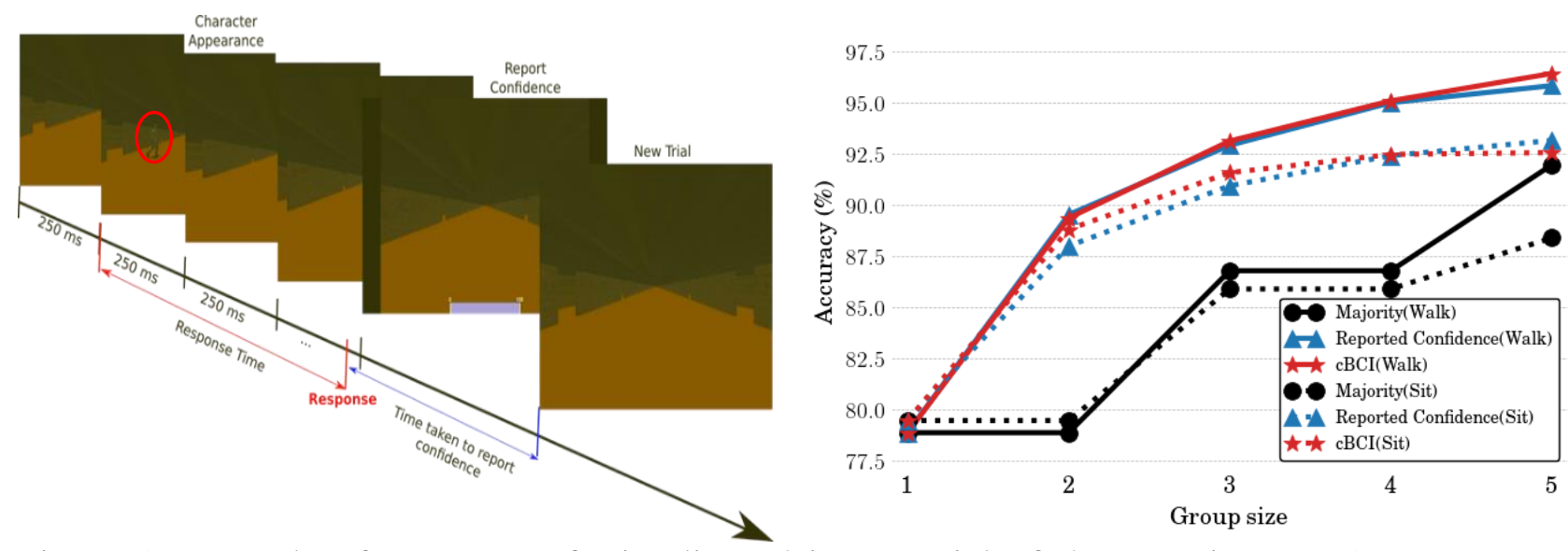

Figure 1. Example of sequence of stimuli used in one trial of the experiment. Average group accuracies for groups of size 1 to 5 using standard majority (in black), reported confidence (in blue), and cBCI (in red) while sitting (dashed lines) and walking (solid lines).

\section{CONCLUSIONS}

While muscular artefacts caused by walking on a treadmill could be expected to produce negative effects on the ability of the cBCI to decode the decision confidence of users, the similarity between the $\mathrm{cBCI}$ and reported confidence performance in both the walking and sitting conditions indicates otherwise. Instead, we found that walking improves group performance in the task considered in this paper, which is likely due to increased level of alertness, leading to overall better performance, in the walking conditions. This suggests that the cBCI may work well on a wider range of operating environment than just a lab.

\section{REFERENCES}

[1] Wang, Y., Jung, T.-P. (2011). A Collaborative Brain-Computer Interface for Improving Human Performance. PLoS ONE 6(5): e20422.

[2] Valeriani, D., Poli, R., \& Cinel, C. (2017). Enhancement of Group Perception via a Collaborative Brain-Computer Interface. IEEE Transactions on Biomedical Engineering, 64(6), 1238-1248.

[3] Valeriani, D., Cinel, C., \& Poli, R. (2017b). Group Augmentation in Realistic Visual-Search Decisions via a Hybrid Brain-Computer Interface. Scientific reports, 7(1), 7772.

\section{ACKNOWLEDGMENTS}

This research was supported by the Defence Science and Technology Laboratory (Dstl) on behalf of the UK Ministry of Defence (MOD). 